UCRL-ID-135141

\title{
X-Ray Waveguides for High Resolution X-Ray Analysis
}

Troy W. Barbee, Jr.

June 28, 1999

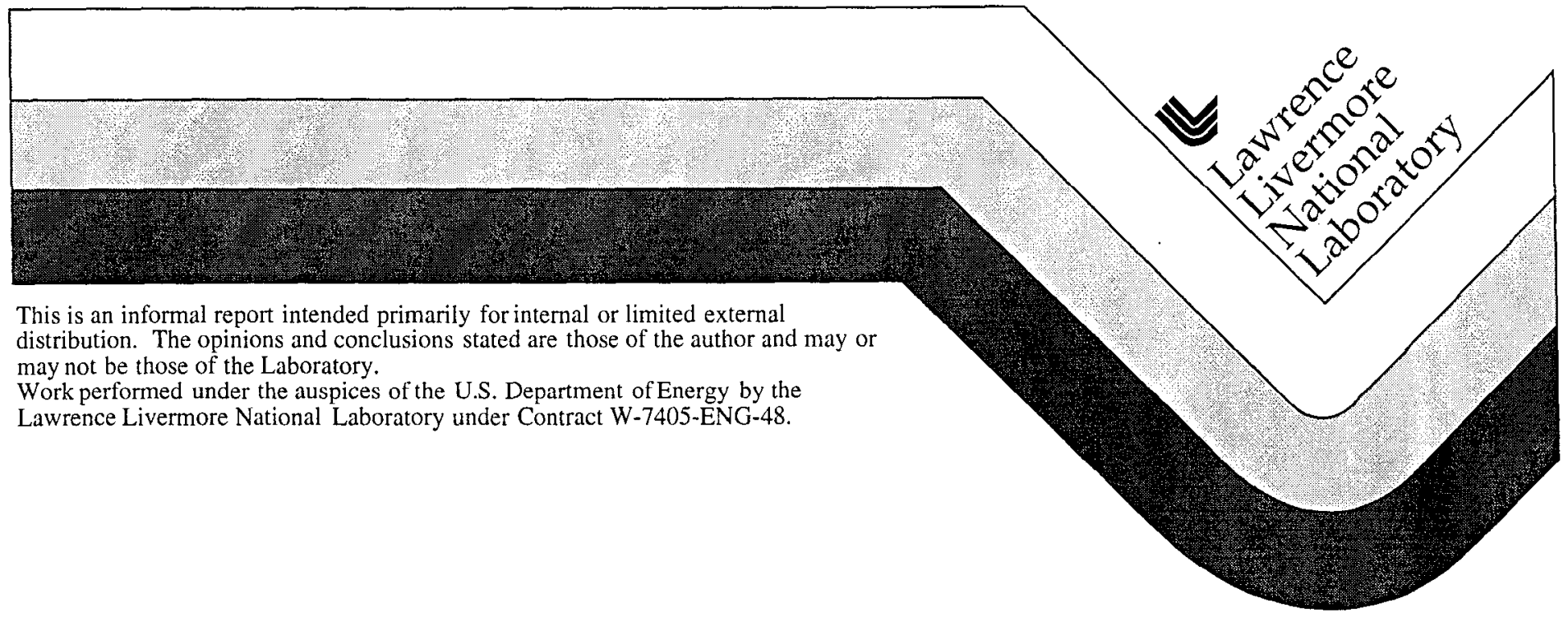




\section{DISCLAIMER}

This document was prepared as an account of work sponsored by an agency of the United States Government. Neither the United States Government nor the University of California nor any of their employees, makes any warranty, express or implied, or assumes any legal liability or responsibility for the accuracy, completeness, or usefulness of any information, apparatus, product, or process disclosed, or represents that its use would not infringe privately owned rights. Reference herein to any specific commercial product, process, or service by trade name, trademark, manufacturer, or otherwise, does not necessarily constitute or imply its endorsement, recommendation, or favoring by the United States Government or the University of California. The views and opinions of authors expressed herein do not necessarily state or reflect those of the United States Government or the University of California, and shall not be used for advertising or product endorsement purposes.

This report has been reproduced directly from the best available copy.

Available to DOE and DOE contractors from the Office of Scientific and Technical Information

P.O. Box 62, Oak Ridge, TN 37831

Prices available from (615) 576-8401, FTS 626-8401

Available to the public from the

National Technical Information Service

U.S. Department of Commerce

5285 Port Royal Rd.,

Springfield, VA 22161 
Proposal No. 9954

\title{
X-RAY WAVEGUIDES FOR HIGH RESOLUTION X-RAY ANALYSIS
}

\author{
Troy W. Barbee, Jr. \\ Lawrence Livermore National Laboratory \\ Livermore CA 94550
}

\section{Introduction}

The project goals were to model, synthesize, and characterize thin-film, $x$-ray waveguide structures to determine whether such nanostructures can be fabricated with the precision required for true waveguide operation at $x$-ray energies. In FY98, we designed, fabricated, and characterized (at the Stanford Synchrotron Radiation Laboratory) optimized, thin-film, $x$-ray waveguide structures (XWGs) as resonant concentrators of $\mathrm{x}$-rays which may be applied as diffraction-limited, linear $\mathrm{x}$-ray sources. We fabricated nine waveguide structures that were optimized to operate in the cavity modes $m=1,2,3$ and tested them at $x$-ray energies of 6 to $10 \mathrm{keV}$. The observed performances were compared to the calculations based on the design structures and excellent agreement was demonstrated.

This project plan is presented in TABLE 1 that includes all aspects of the development of these unique thin film $x$-ray optical devices. X-ray waveguide designs were made using a standard $x$-ray multilayer $x$-ray optic Fresnel code. Materials were selected on the basis of calculated performance as well as sputter deposition characteristics. Laboratory $\mathrm{x}$-ray reflectivity measurements were made prior to the SSRL experimental run to assess the quality of the samples. Cross-section Transmission Electron Microscopy observations of selected sample were made to enable assessment of the relationship between the design structures and the fabricated structures. The cross-section TEM observations correlated well with the waveguide fabrication parameters supporting the observed agreement hetween the experimental and calculated grazing incidence reflectivities and fluorescence as functions of both $\mathrm{x}$-ray energy and grazing angle of incidence.

TABLE 1.

\section{X-ray Waveguide Project}
A.X-ray Waveguide A Cavity
Design/Model Calculations
1. As a function of Cavity Structure;
3. As a function of Wavelength
2. As a function of Cavity Materials;
4. As a function of Waveguide Mode

B.X-ray Waveguide Cavity Fabrication
1. Multilayer Synthesis process;
2. Substrates

3. Preparation of the Cavity Termination Emitting Surface

C. X-ray Waveguide Cavity-Laboratory Characterization

1. X-ray Reflectivity/Fluorescence 2. LLNL SEM/TEM Structural Characterization

a. LLNL Laboratory

a. Plan View and Cross-Section View

b. Synchrotron

b. Interfacial Structure

D. Waveguide Performance-Synchrotron

1. As a function of Waveguide Structure

2. As a function of Waveguide Materials

3. As a function of Wavelength

4. As a function of Waveguide Mode

5. Comparison With Model Calculations

The wave guide structures were fabricated onto $x$-ray optic quality fused silica flats $(<0.1 \mathrm{~nm} \mathrm{rms})$, $\mathrm{x}$-ray optic quality super polished single crystal silicon blocks (l"x 1"x4") and device quality (100) single crystal silicon wafers by magnetron sputter deposition. Laboratory $\mathrm{x}$-ray characterization was made with $\mathrm{Cu}$ $\mathrm{K}_{\alpha}(1.5418 \AA)$ using the silicon single crystal wafer samples as were the transmission electron microscopy cross-section observations. Synchrotron radiation experiments were performed on Beam Line 10-2 using 
(111) water cooled crystals calibrated at the $\mathrm{Cu} \mathrm{K}$ edge. This beam line was run unfocused with graphite filters in the beam. SSRL Grazing incidence XAS equipment and an SSRL 13 element Ge energy dispersive detector array were used in these experiments to detect $\mathrm{Cu} \mathrm{K}_{\alpha}$ and $\mathrm{Ta} \mathrm{L}_{\alpha}$ fluorescence from component layers in the wave guides. This equipment made possible very accurate grazing incidence alignment and angular scans at a minimum angular step size of 0.25 mdeg $(4.36 \mu$ radians). As will be shown in the discussion of the experimental results the 13 element Ge detector made possible measurements of $\mathrm{x}$-ray fluorescence from material layers in the wave guide structures. In one case a $0.4 \mathrm{~nm}$ Ta layer was intentionally positioned in the center of the waveguide cavity as a marker layer to make possible quantitative demonstration of $\mathrm{x}$-ray waveguide performance.

This wave guide (Ambient / 4nm B ${ }_{4} \mathrm{C} / 2.2 \mathrm{~nm} \mathrm{~W} / 15 \mathrm{~nm} \mathrm{~B}_{4} \mathrm{C} / 0.4 \mathrm{~nm} \mathrm{Ta} / 15 \mathrm{~nm} \mathrm{~B}{ }_{4} \mathrm{C} / 50 \mathrm{~nm} \mathrm{~W}$ / Substrate) was designed to sample the cavity standing wave fields at $\mathrm{x}$-ray energies of 80 to $10 \mathrm{keV}$ by placing a $0.4 \mathrm{~nm}$ Ta layer at the center of the cavity and measuring the angular dependence of the $\mathrm{Ta} \mathrm{L}$ $(8.146 \mathrm{keV})$ fluorescence intensity at fixed $\mathrm{x}$-ray energies of 9.881 and $10 \mathrm{keV}$. The minima in the reflectivity as shown in Figure 1 are the angular positions of the cavity modes $m=1,2,3,4,5$. The maxima in the cavity standing wave fields at the Ta layers at the cavity center will occur for the odd cavity modes $\mathrm{m}=1,3,5$ and the minima for even cavity modes $-\mathrm{m}=2,4,6$. Thus, the Ta fluorescent intensity is expected to be maximum for the odd modes - $m=1,3,5$ and minimum for the even modes - $m-2,4,6$ as seen in Figure 2 .

The primary conclusion from these experiments is that multilayer technology as applied to $x$-ray optic fabrication is sufficiently precise to enable fabrication of $x$-ray waveguides that show performance at levels predicted for ideal structures or samples.

Many other x-ray waveguide structures were also fabricated and experimentally characterized. These were designed to operate most efficiently in cavity modes $m=1,2$ and 3 and such behavior demonstrated. The effect of cavity size was also evaluated and performance in agreement with calculation observed. In addition samples werc fabricated that made possible the determination of the $x$-ray intensity at the surface of the wave guide structure. This was accomplished again by fabricating the wave guide structure using a material that would fluoresce thus providing a measure of the local $x$-ray intensity. One of these wave guides had a structure - Ambient / $55 \mathrm{~nm} \mathrm{~B} \mathrm{~B}_{+} \mathrm{C} / 2 \mathrm{~nm} \mathrm{Cl} / 30 \mathrm{~nm} \mathrm{~B}{ }_{4} \mathrm{C} / 50 \mathrm{~nm} \mathrm{~W} /$ Substrate. Determination of the reflectivity and the intensity of the $\mathrm{Cu} \mathrm{K}$ fluorescent intensity as a function of the grazing angle of incidence for incident $x$-ray energics above approximately $9 \mathrm{keV}$ made possible determination of the surface $\mathrm{x}$-ray intensity in the $\mathrm{Cu}$ layer. The reflectivity and $\mathrm{Cu} \mathrm{K}$ fluorescence observed are shown in Figure 3 and compared to model calculations. The agreement is excellent in both cases and demonstrates $\mathrm{x}$-ray wave guide behavior in this type of structure.

The results presented in Figure 3 again demonstrate the very good agreement between experimental observations and model calculations of $x$-ray waveguide performance. The implications of this are quite striking in that these structures are $x$-ray concentrators and have the potential application as micro $\mathrm{x}$-ray sources with dimensions at the $50 \mathrm{~nm}$ or less levels. This is best demonstrated by calculations of the intensities in the wave guide modes in a model system optimized to have very high guided wave intensity in the mode $m=1$. the results of these calculations are presented in Figure 4.

The calculated intensitics at the wave guide cavity center presented in Figure 4 are 118 for $n=1,50$ for $n=2,26$ for $n=3$ and 14 for $n=4$. Additionally, the full width half maximum of the $n=1$ maxima is almost exactly $300 \AA$. Thus, this device can concentrate the $x$-rays in an incident beam that may be $300 \AA$ in scale to more than 100 times its original intensity. This source size is more comparable to $\mathrm{x}$-ray wavelengths than we are normally accustomed. thus, it is important to note that this source will, in all probability, be a diffraction limited source. Application of these waveguides as microbeam structures will therefor require reimaging of the source by more traditional methods such as $\mathrm{K}-\mathrm{B}$ optic. In any case, the potential for $x$-ray beams in the $100 \AA$ to $300 \AA$ size range has been demonstrated and offers unique possibilities for $x$-ray analysis as well as $x$-ray science. 

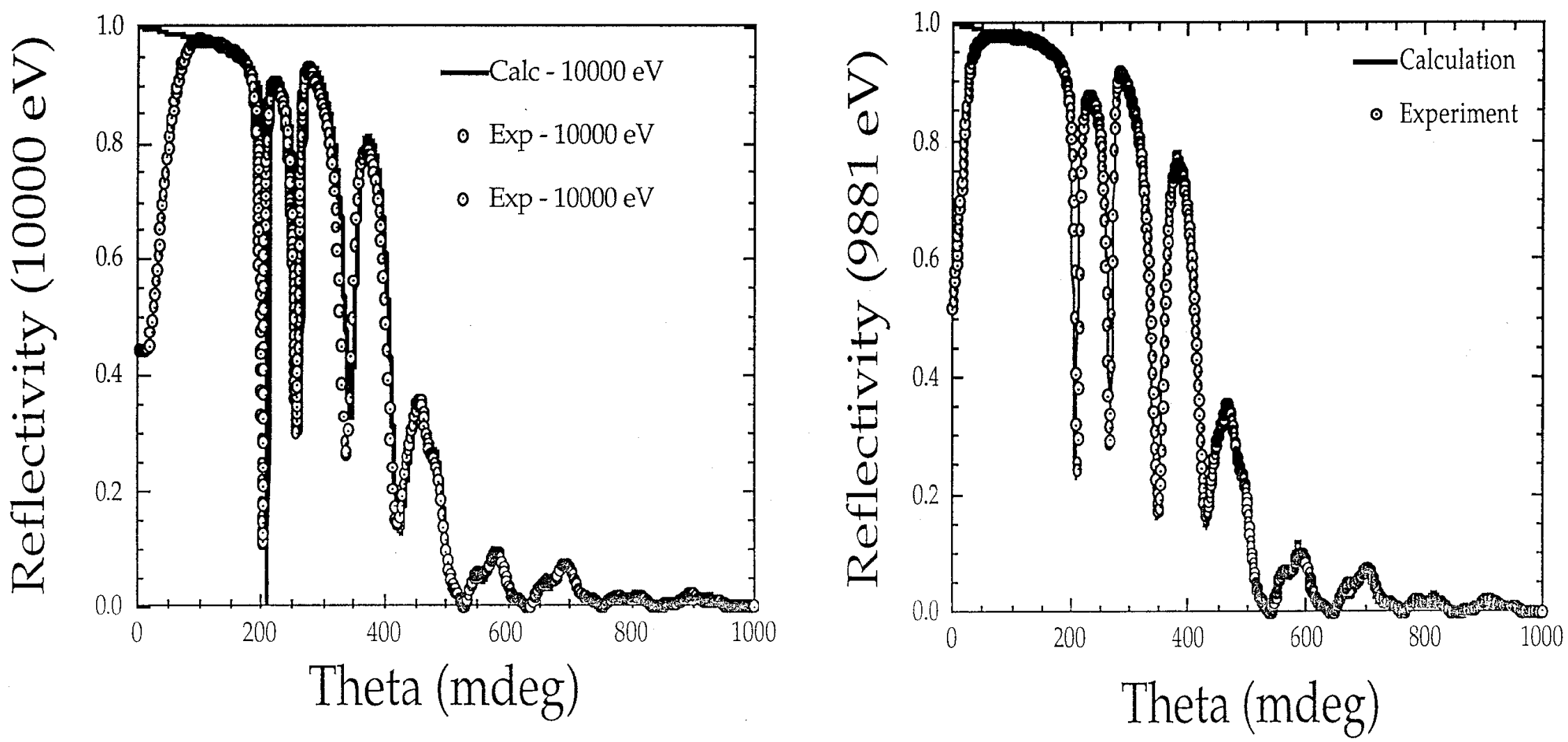

Figure 1. The grazing incidence reflectivity at $10 \mathrm{keV}$ and $9.881 \mathrm{keV}$ of sample $98-107$ is shown and compared to model calculations as a function of the angle of incidence. 

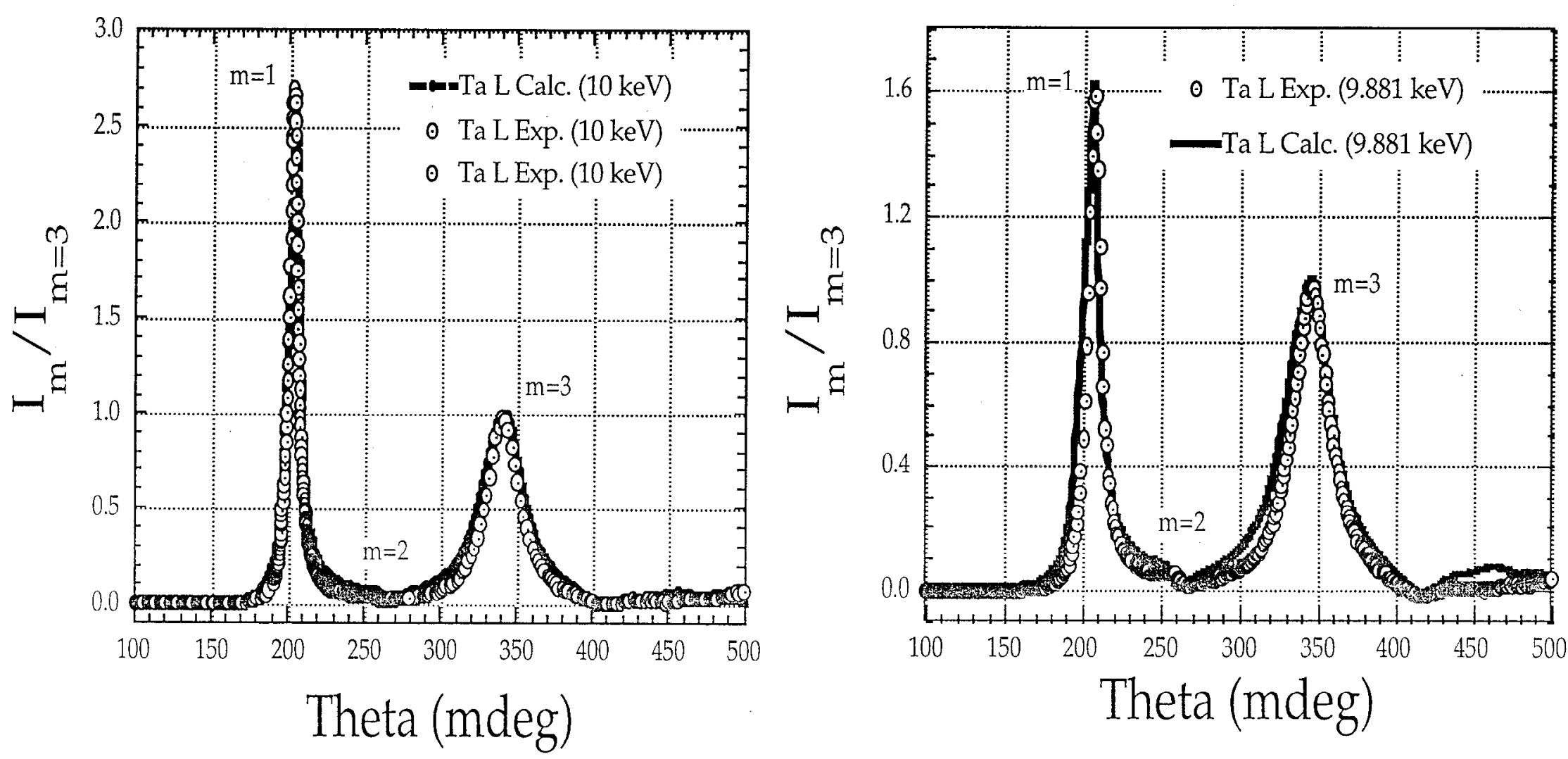

Figure 2. Experimental Ta L fluorescence generated by the wave guide modes $m=1,2,3,4,5$ by 9.881 and $10 \mathrm{keV} x$-rays are shown and compared to model calculations. The excellent agreement between cxpcriment and calculation shown supports the conclusion that $x$-ray wave guide performance was observed. 

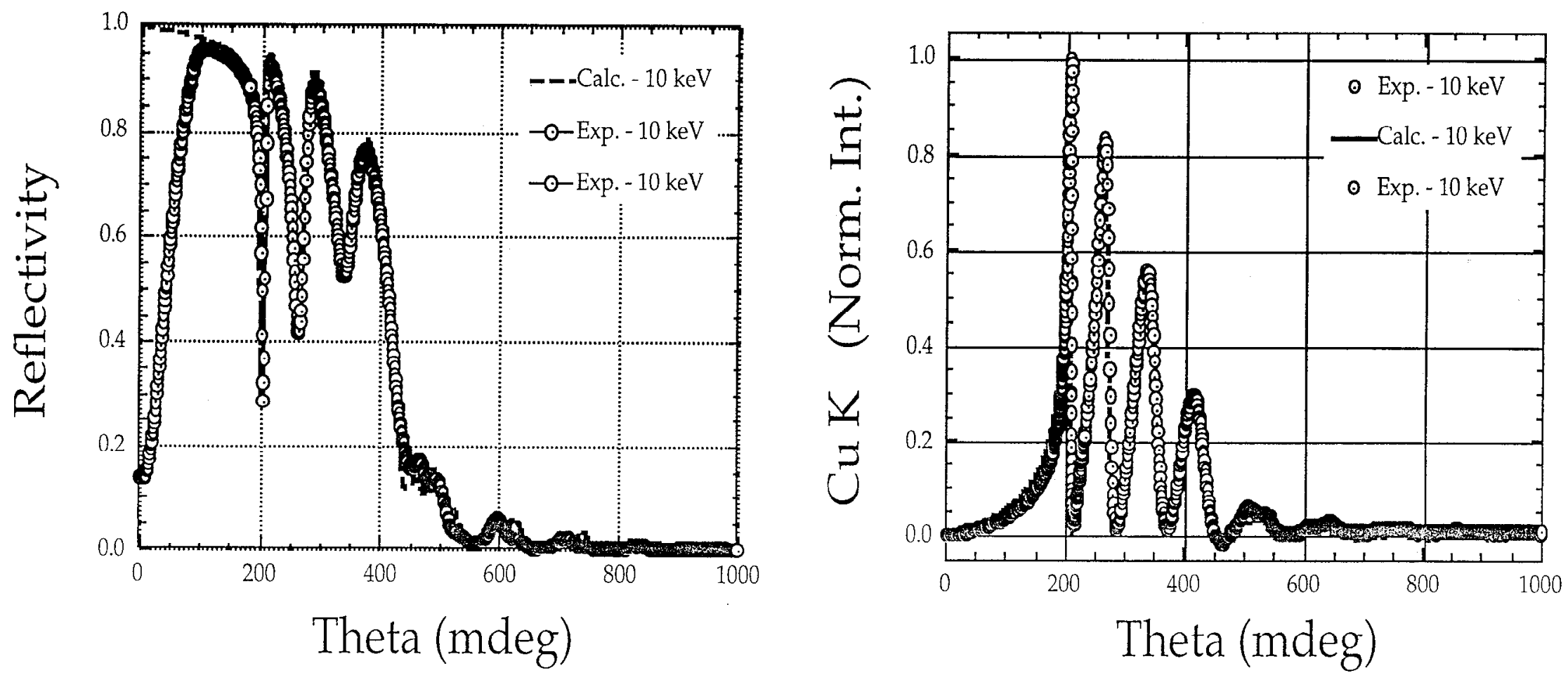

Figure 3. The experimental reflectivity of $10 \mathrm{keV} \mathrm{x}$-rays from a wave guide (Ambient $/ 55 \mathrm{~nm} \mathrm{~B} \mathrm{~B}_{4} \mathrm{C} / 2 \mathrm{~nm} \mathrm{Cu} / 30 \mathrm{~nm} \mathrm{~B}{ }_{4} \mathrm{C} / 50 \mathrm{~nm} \mathrm{~W} / \mathrm{Substrate}$ ) is shown as a function of the grazing angle of incidence and compared to calculation. The $\mathrm{Cu} K$ fluorescent intensity from the $2 \mathrm{~nm} \mathrm{Cu}$ layer at the surface of the wave guide is also shown and compared to calculation. Exccllent agreement is seen in both the figures presented. 


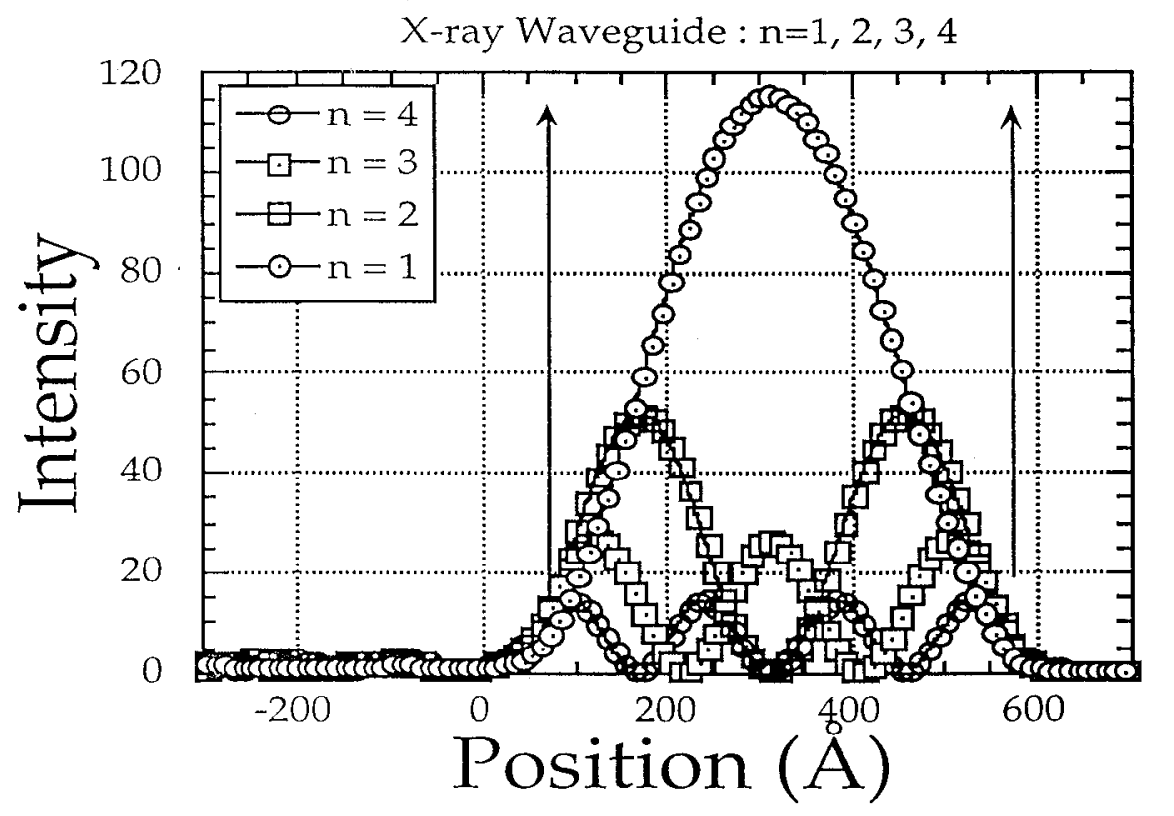

Figure 4. Calculated standing wave intensities in a thin film $x$-ray waveguide having a $500 \AA$ cavity optimized for operation in its first mode $(n=1)$ are shown as a function of depth into the structure. These modes occur at increasing angles of incidence with the $\mathrm{m}=1$ mode at an angle of approximately $0.2 \mathrm{deg}$. Note that the $n=1,3$ modes have maxima in the center of the wave guide cavity as discussed above.

\section{CONCLUSIONS}

The range of materials science, chemistry, physics, and technology-based problems to which these $x$-ray waveguides and associated instrumentation could contribute is very large. The scientific and programmatic importance is multifaceted. In general, the ability to quantitatively characterize the crystallographic and the compositional distributions in macroscopic samples at sub $100 \mathrm{~nm}$ resolutions opens the community to a whole new range of understanding of synthesis/structure/property relationships. This is at the core of materials science and will enable materials engineering at the mesoscopic scale. This technique will not reach the truly microscopic or atomic scale but will provide a tool to study materials in a quantitative manner at that intermediate level between microscopic and macroscopic as well as potentially providing new microbeam sources for the tomography and structural determination of protein structure.

\section{ACKNOWLEDGMENTS}

This work was performed under the auspices of the U.S. Department of Energy by the Lawrence Livermore National Laboratory under Contract No.W-7405-ENG-48. UC-National Laboratory Participating Research Team facilities (BL 10-2) at the Stanford Synchrotron Radiation Laboratory (SSRL) were applied in this study. SSRL operates under the support of the U. S. Department of Energy.

I also wish to acknowledge the effective efforts of TAI NGUYEN, LLNL; GARY JOHNSON, LLNL; FRANS WEBER, LLNL; and ROMAN TATCHYN, SSRL in the performance of these experiments on BL-10-2 at SSRL. Also, the SSRL staff supporting the GIXAFS apparatus were on the spot and provided exceptional aid in setup, teaching the vagaries of the apparatus and helping repair it when it went down. 